\title{
Density based Traffic Management System using Image Processing
}

\author{
Vikram $\mathbf{R}^{1}$, Kalaivani $\mathbf{T}^{2}$, Kanimozhi $\mathrm{A}^{3}$, Ranjani $\mathrm{V}^{4}$, Reena $\mathrm{D}^{5}$ \\ ${ }^{1}$ Department of CSE, M.Kumarasamy College of Engineering, India, vikramr.cse@mkce.ac.in \\ ${ }^{2}$ Department of CSE, M.Kumarasamy College of Engineering, India, kalaivanithangavel1998@ gmail.com \\ ${ }^{3}$ Department of CSE, M.Kumarasamy College of Engineering, India, kani849aruchamy@gmail.com \\ ${ }^{4}$ Department of CSE, M.Kumarasamy College of Engineering, India, ranjaniv1998@gmail.com \\ ${ }^{5}$ Department of CSE, M.Kumarasamy College of Engineering, India, reenaduraicute@gmail.com
}

\begin{abstract}
Traffic congestion in metropolitan areas is the major problem faced in today's life. The vehicles are increased at a high rate leads to traffic congestion at both peak and non-peak hours. This causes less efficient traffic control management of roads. Traffic light control systems are based on a fixed time interval of the traffic signals. These time- based signals will waste the time for the side of a small number of vehicles on the road which exceeds another road of vehicles at a high rate to wait for a long time. The advance system focuses on time wasted for vehicles of a road at a low rate. It allocates time to calculate the density of the vehicles. Using pattern matching in image processing we are proposing an efficient traffic control system.
\end{abstract}

Key words: Density of vehicle, Image processing, LabVIEW software, Pattern matching,

\section{INTRODUCTION}

Traffic congestion control is the demand one to acquire life easy at roads. The need for sleek flow of vehicles is awaited by everyone in daily life. Most of the traffic signal timings are pre-programmed that not suited for real-time traffic situations. For this issue, we propose a system which foretells the number of vehicles on the road by measuring the density of vehicles. The pattern matching algorithm in image processing is used to measure the density of vehicles. It is measured by drawing a diamond-shaped pattern on the road. The required number of a diamond-shaped pattern is drawn to some distance. The density of the vehicles is taken when the vehicles placed above on it in any part of a shape that drawn. First, we capture the image of the road with no vehicles of the empty pattern only. It will be processed with the image of vehicles standing on a pattern in a traffic junction. The software will compare both images by matching an empty pattern on a road. Consider if twenty patterns drawn for some distance and eleven vehicles are standing on the road covering a diamond pattern. The image will be captured by a camera and compared by matching the pattern with a base image. If there are eleven patterns not matching and the remaining ten patterns are matching then it results in the count of vehicles as eleven. After got the density of vehicles the time interval for the green signal of a traffic light is calculated based on a certain formula and it will be projected on traffic display. It makes the people do not want to wait for a long time in the traffic signal.

\section{LITERATURE REVIEW}

Several kinds of research and techniques have been proposed to control the traffic in complex situations.

Shibin Balu et al. [1] has proposed an image processing technique using MATLAB for a count of vehicles. Cameras are installed to capture videos and send them to MATLAB software for further process. The videos are taken every 10 seconds to find the traffic level. This system will take high time because of frequent video capture and processing.

Wahban Al okaishi et al. [2] has proposed a model to control traffic by applying the background updating and edge detection of image processing. The algorithm used is background updating, edge detection, traffic volume estimation. They separate the edge of the vehicles to find the density of vehicles from the edges of objects of the background.

Bilal Ghazal et al. [3] has discussed a model to deliver a system for traffic jam and congestion. These systems use hardware such as PIC microcontroller and valuate traffic density with the help of IR sensors and calculate the time slots at each level of the traffic.

Anna Merine George et al. [4] has developed a system uses IOT and Adaptive Neuro Fuzzy Inference System (ANFIS) for traffic management. A camera is used to capture the image and using Arudino UNO and Think Speak Platform the image is transferred to cloud. Then those images are analyzed using 
ANFIS controller. Several steps are taken to time interval hence it consumes more time.

Elizabeth Basil et al. [5] have proposed a system of traffic control based on IOT. This system delivers and transfers the count of vehicles to the next traffic junction for control the next signal. It uses different technology for each part of the system. Image processing and MATLAB for process traffic video and the count of vehicle is done by raspberry pi.

\section{PROPOSED SYSTEM}

Pattern matching algorithm plays a vital role in many applications and here it is used to identify the density of the vehicle while the traffic signal is in progress. This proposed method will give a betterment result to the smart cities as a smart traffic signal in a four-way junction. The pattern matching algorithm is done using the LabVIEW platform. The proposed method is fixing time for red and green light based on the density or number of vehicles in the road waiting for a signal.

There are four stages in image processing are techniques are involved for the system:

1. Vision acquisition

2. Vision assistant

3. Compare vision

4. Signal calculation

A. Vision acquisition:

The images have been captured for every second with the help of cameras which is placed in four-way junction. With the help of the captured images have to find the pattern present in it.

B. Vision assistant:

The patterns identified from the vision acquisition are matched with the reference pattern in the LabVIEW platform. For example, the reference pattern is taken as a diamond-shaped pattern (Top and right side of the diamond pattern is connected by a right angle 90 degrees). Then find the numbers of patterns matched with the captured image.

\section{Compare vision:}

To find the matched pattern in the four-way junction. Compare the count of the found matched patterns among the four-way.

D. Signal calculation:

The way which has the minimum count of the matched pattern is considered as a first priority, so the green light will be enabled based on the density of the vehicles and also vice versa (maximum count - red).

\section{METHODOLOGY}

The architecture of the traffic signal timing control system is delivered as

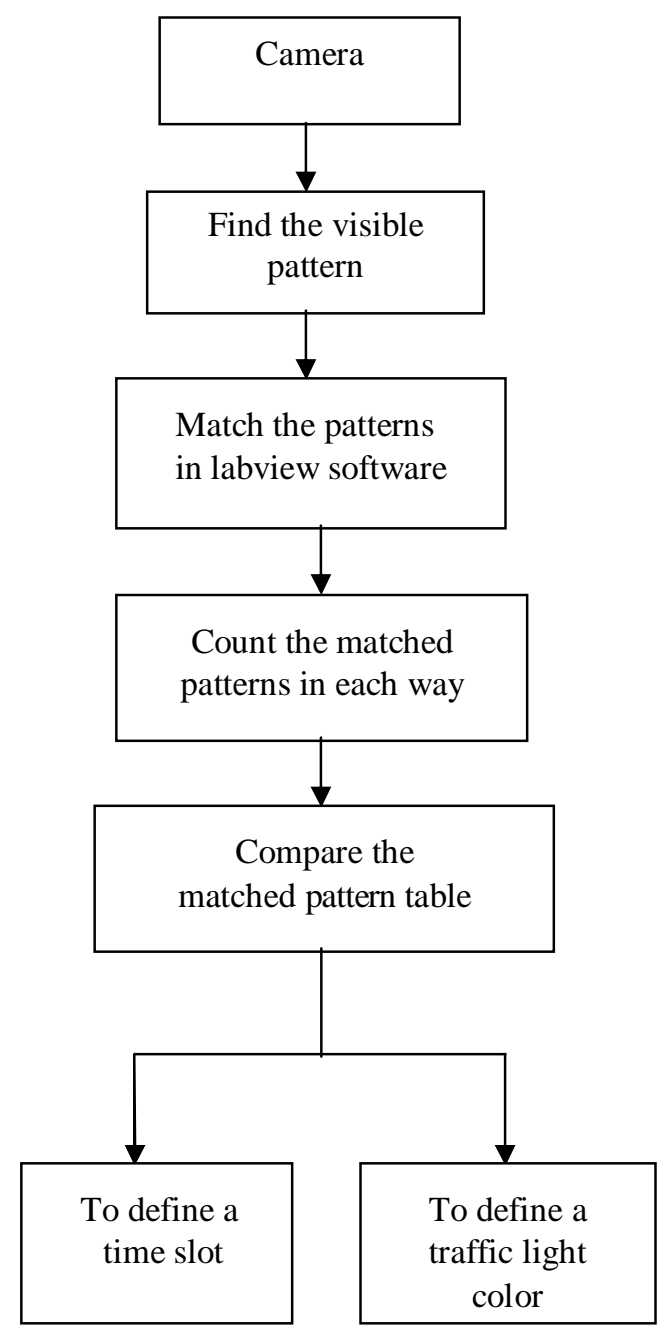

Figure 1: Architecture of the traffic signal control system

The digital image processing technique is capable of a process in the real- time images to monitor the vehicle density based on a pattern-matching algorithm. The camera will starts capturing images in terms of match the patterns that drawn on the road to check whether the patterns are filled with vehicles or not.

Compute the number of vehicles by identifying the number of patterns matched and by identifying the number of patterns unmatched to allot time for the green signal as unmatched pattern number is based on the density of the traffic.

The algorithm used in this system is explained in Fig.2. The initial step of the algorithm is to capture image full of diamond-shaped patterns with no vehicles on the road. 

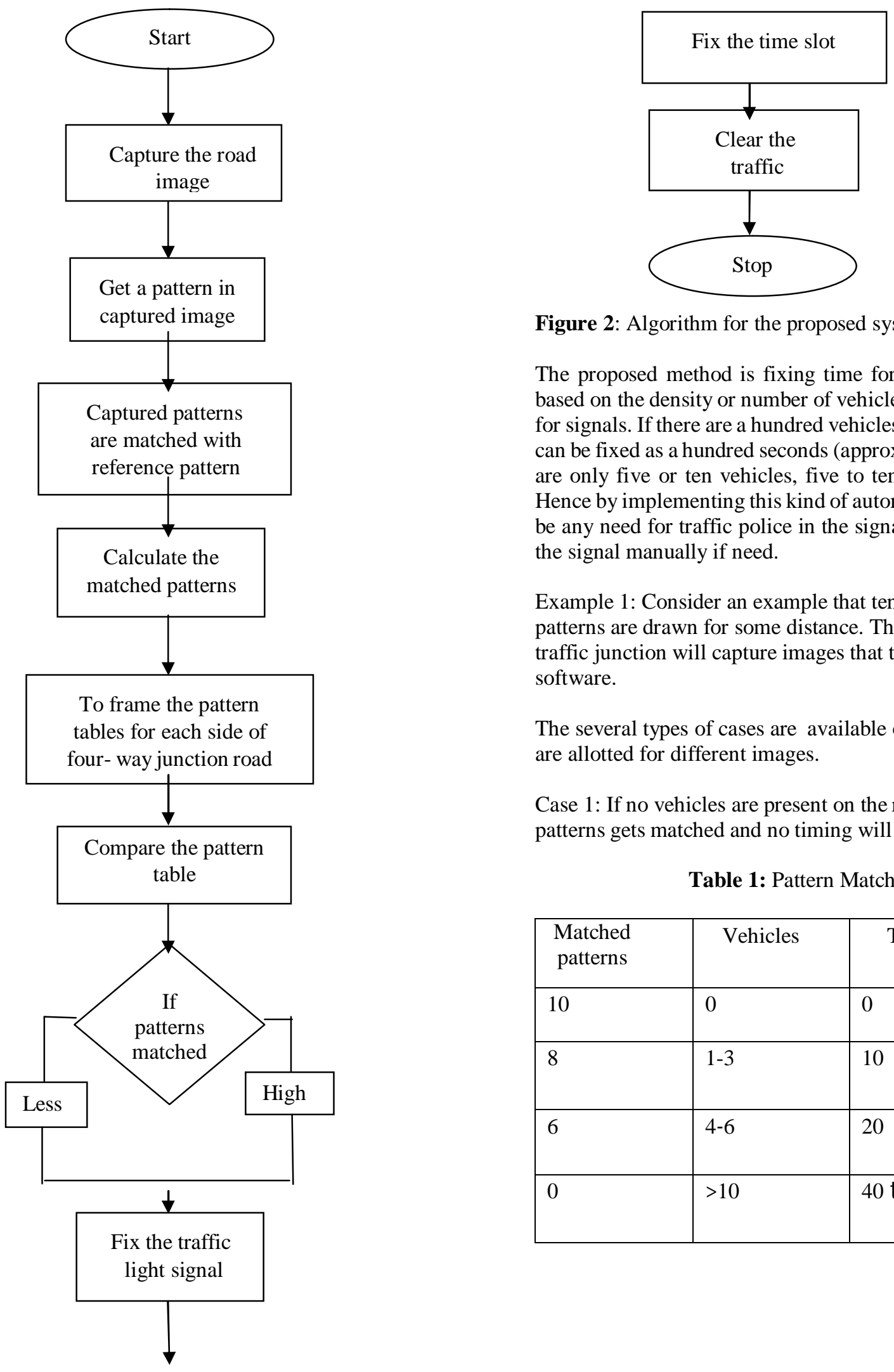

Figure 2: Algorithm for the proposed system

The proposed method is fixing time for red and green light based on the density or number of vehicles in the road waiting for signals. If there are a hundred vehicles on the road the time can be fixed as a hundred seconds (approximately) and if there are only five or ten vehicles, five to ten seconds is enough. Hence by implementing this kind of automation, there will not be any need for traffic police in the signal and also to control the signal manually if need.

Example 1: Consider an example that ten diamond-shaped patterns are drawn for some distance. The camera placed on traffic junction will capture images that to be processed by software.

The several types of cases are available on how the timings are allotted for different images.

Case 1: If no vehicles are present on the road then all ten patterns gets matched and no timing will be allotted.

Table 1: Pattern Matching

\begin{tabular}{|l|l|l|}
\hline $\begin{array}{l}\text { Matched } \\
\text { patterns }\end{array}$ & Vehicles & Timer(sec) \\
\hline 10 & 0 & 0 \\
\hline 8 & $1-3$ & 10 \\
\hline 6 & $4-6$ & 20 \\
\hline 0 & $>10$ & 40 to 50 \\
\hline
\end{tabular}


Case 2: If eight patterns are matched and two patterns are not matched. The patterns that not matched are the density of vehicles. Hence based on it the timing from one second to three second for the signal is allotted.

Case 3: There are zero patterns that not matched then first priority for the signal is given and time is allotted in high range.

\section{EXPERIMENTAL RESULTS}

Experimental problem:

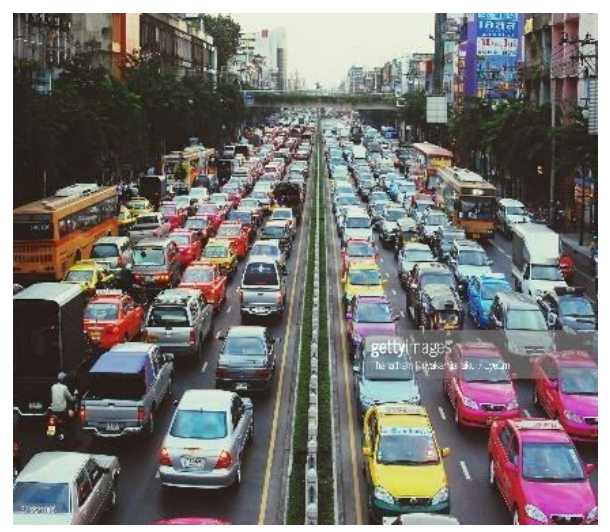

Figure 3: Model 1

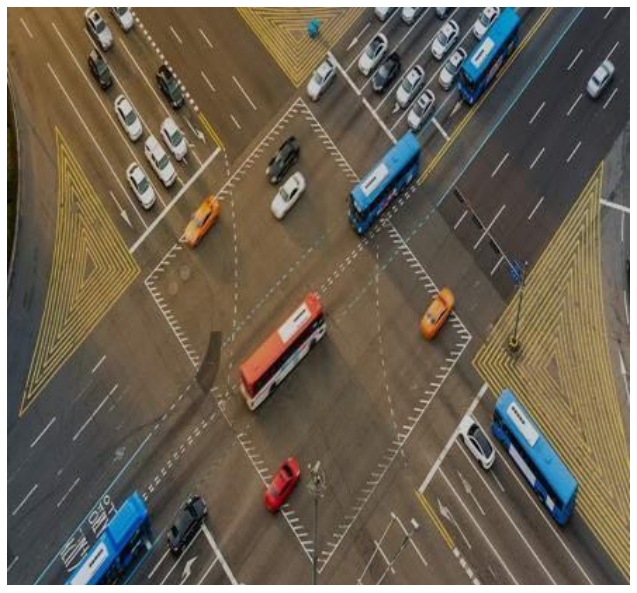

Figure 4: Model 2

Experimental solution:

The proposed and advanced model will be designed and look like image shown below

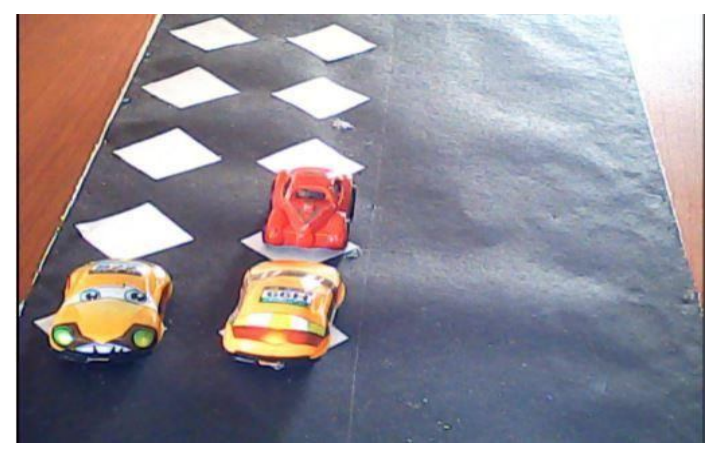

Figure 5: Model 3

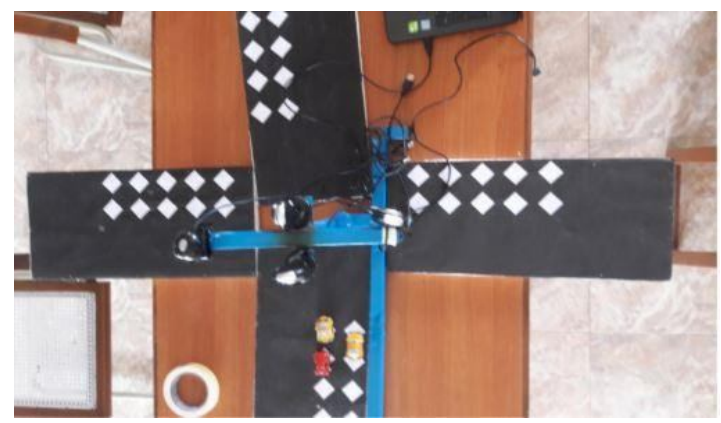

Figure 6: Model 4

\section{CONCLUSION}

A real-time advanced traffic light control system is delivered in this paper. This advanced system will process both peak and non-peak hours which will work for all hours. The pattern matching algorithm of image processing will give efficient traffic management by controlling the traffic junction to help the people who riding the vehicles, who crossing the road and for all those who use the road. So, people will have a peaceful life on the roads. By this advanced model, people have not to spend more time at traffic junction for the signal. The time interval for their vehicles will be allotted in a quick and fast manner in an efficient way.

\section{REFERENCES}

1. Munir Hasan, Gobinda Saha, Aminul Hoque and Md. Badruddoja Majumder "Smart Traffic Control System with Application of Image Processing Techniques" 2014 IEEE https://doi.org/10.1109/ICIEV.2014.6850751

2. Bilal Ghazal, Khaled EIKhatib, Khaled Chahine and Mohamad Kherfan "Smart Traffic Light Control System" 2016 IEEE https://doi.org/10.1109/EECEA.2016.7470780

3. Wahban Al okaishi,, Issam Atouf and Mohamed Benrabh "Smart Controlling for Traffic Light Time" 2017 IEEE

4. Elizabeth Basil and S.D.Sawant "IoT based Traffic Light Control System using Raspberry Pi” 2017 IEEE 
5. Ala'a Abu Zaid, Yazan Suhweil and Musa Al Yaman "Smart Controlling for Traffic Light Time" 2017 IEEE

6. Aneesa Saleh, Steve A. Adeshina, Ahmad Galadima and Okechukwu Ugweje "An Intelligent Traffic Control System" 2017 IEEE

7. Swapnil Manohar Shinde "Adaptive Traffic Light Control System" 2017 IEEE

8. Khushi "Smart Control of Traffic Light System using Image Processing" 2017 IEEE

9. Taqi Tahmid and Eklas Hossain "Density Based Smart Traffic Control System Using Canny Edge Detection Algorithm for Congregating Traffic Information" 2017 IEEE https://doi.org/10.1109/EICT.2017.8275131

10. Mohamad Belal Natafgi, Mohamad Osman, Asser Sleiman Haidar and Lama Hamandi "Smart Traffic Light System Using Machine Learning" 2018 IEEE

11. Anna Merine George, Mary Ann George and V.I.George "IOT based Smart Traffic Light Control" 2018 IEEE

12. Shibin Balu and C Priyadharsini "Smart Traffic Congestion Control System" 2019 IEEE

13. Alvin S. Alon, Rufo I. Marasigan, Jr., Jennalyn G. Nicolas- Mindoro, Cherry D. Casuat "An Image Processing Approach of Multiple Eggs Quality Inspection" ,International Journal of Advanced Trends in Computer Science and Engineering, Volume 8, No.6, November - December 2019 https://doi.org/10.30534/ijatcse/2019/18862019

14. T.C. Sandanayake , A.M. Bandara "Automated Classroom Lecture Note Generation Using Natural Language Processing and Image Processing Techniques", International Journal of Advanced Trends in Computer Science and Engineering, Volume 8, No.5, September - October 2019 https://doi.org/10.30534/ijatcse/2019/16852019

15. S. Saravanan, R. Vikram "Improved performance analysis image segmentation based on cluster image" Journal of chemical and pharmaceutical science, issue on February 2017.

16. S.Sravanan , T.Abiramai , and P.Pandiaraja 2018, 'Improve Efficient Keywords Searching Data Retrieval Process in Cloud Server ", 2018 International Conference on Intelligent Computing and Communication for Smart World (I2C2SW) .PP 219 $-223$.

17. P.RajeshKanna and P.Pandiaraja 2019," An Efficient Sentiment Analysis Approach for Product Review using Turney Algorithm", Journal of Procedia Computer Science, Elsevier, Vol 165 ,Issue 2019, Pages 356-362.

18. N Deepa , P. Pandiaraja," Hybrid Context Aware Recommendation System for E-Health Care by merkle hash tree from cloud using evolutionary algorithm" , Journal of Soft Computing, Springer , 2019.

https://doi.org/10.1007/s00500-019-04322-7 